http://jmscr.igmpublication.org/home/

ISSN (e)-2347-176x ISSN (p) 2455-0450

crossref DOI: https://dx.doi.org/10.18535/jmscr/v7i7.23

\title{
Our Study on Current Role of Laparoscopy in Colorectal Malignancy in Comparison to Open Surgery
}

\author{
Authors \\ Dr N.Shanmuga Sankar Ram ${ }_{* 1,3}$, Dr S.Navaneetha Krishnan ${ }^{2}$, Dr N.Junior Sundresh ${ }^{3 *}$ \\ ${ }^{* 1,3}$ Professor, Department of Surgery, R.M.M.C.H, Annamalai University \\ ${ }^{2}$ Assistant Professor, Department of Surgery, R.M.M.C.H, Annamalai University \\ *Corresponding Author \\ Dr N.Junior Sundresh \\ Professor, Department of Surgery, R.M.M.C.H, Annamalai University
}

\begin{abstract}
Aim: To evaluate the usefulness of laparoscopic colorectal surgeries as safe, oncologic, operative approach versus open colorectal surgeries. Our study intends to analyze \& review the current role of laparoscopy in colorectal malignancy in comparison to open surgery

Materials and Method: A total of 40 patients were operated for colorectal malignancies, 25 by open technique and 15 by laparoscopic technique.. Based on the site of tumour, standard surgical procedures were performed either by laparoscopic or by open technique. Patients were followed up periodically and details with regard to hospital stay, post-operative complications, oncological clearance \& recurrence were recorded. Patients were followed up for a mean period of 3-24 months.

Conclusion: Laparoscopy has undoubtedly surpassed open surgery with its benefits of smaller incision, reduced postoperative pain, decreased post op narcotic requirement, shorter hospital stay \& quicker recovery.

Keywords: laparoscopic colorectal surgery, open colorectal surgery, and colorectal malignancy.
\end{abstract}

\section{Introduction}

Minimally invasive surgery has gained tremendous popularity and acceptance both with the patients and with the surgeons. ${ }^{1}$ The advent of laparoscopy has brought a lot of changes in the field of surgery especially in terms of patient morbidity and mortality. ${ }^{2}$ With the promise of smaller incision, reduced pain \& quicker recovery, minimally invasive surgery has been applied to an increasing variety of surgical procedures.
Laparoscopy has set path in exploring complex procedures such as colon \& rectal resections over the last 20 yrs. Laparoscopic intestinal resection is a challenge by itself. It demands skill of high magnitude to perform diverse tasks. Laparoscopy is now increasingly performed for benign colorectal diseases although laparoscopic techniques have gone a long way through, oncological surgeons have been slow in adapting to this modality of surgery for fear of oncological 
clearance and port site metastasis. ${ }^{3}$ In the setting of malignancy, concerns over the adequacy of tumour resection, tumour spillage and tumour recurrence were raised, but neither stood the test of time. With evolution of newer techniques and instrumentation, laparoscopy has moved one step ahead in gastro intestinal malignancies, i.e. from diagnostic modality to therapeutic tool in surgeons armamentarium. $^{4}$

\section{Materials and Methods}

Patients subjected to this study were taken from surgical unit of Government Rajaji Hospital, Madurai over a period of two years. A total of 40 patients were operated for colorectal malignancies, 25 by open technique and 15 by laparoscopic technique. Epidemiological factors such as age, sex, previous surgery co morbid illness were taken into account. ${ }^{5}$ Patients were routinely investigated with LFT, USG abdomen and CT abdomen, colonoscopy and barium enema (if indicated). Based on the site of tumour, standard surgical procedures were performed either by laparoscopic or by open technique. ${ }^{6}$ Surgeries were performed by experienced surgeons who were adequately trained in both open and laparoscopic technique. Colorectal cancers were staged according to TNM classification. For laparoscopic surgery, patients with the following criteria were included:

a) Clinical Tis-T2/NO/MO.

b) No bowel obstruction or perforation.

c) No history of major colorectal surgery/ previous laparotomy

d) No prior chemotherapy or radiotherapy or any malignancy

Patients with septic shock, advanced fecal peritonitis, severe cardiovascular and pulmonary disease were not taken for laparoscopic colorectal resection.Locally advanced tumours with or without infiltration into adjacent organs, disseminated malignancies, perorated and obstructed cancers, low lying anaplastic cancers of rectum, prior prostatectomy or radiotherapy for cancer prostate were contraindications for laparoscopic resection. ${ }^{7}$ Taking into consideration the above factors, patients were selected for laparoscopic surgery; conversion to open surgery followed whenever difficulty in laparoscopic surgery was encountered either due to technical Difficulty or complications of anaesthesia. Patients were followed up periodically and details with regard to hospital stay, post-operative complications, oncological clearance \& recurrence were recorded. Patients were followed up for a mean period of 3-24 months. ${ }^{8}$

\section{Statistical Tools}

The information collected regarding all the selected cases were recorded in a Master Chart. Data analysis was done with the help of computer using Epidemiological Information Package (EPI 2010) developed by Centre for Disease Control, Atlanta. Using this software range, frequencies, percentages, means, standard deviations, chi square and ' $p$ ' values were calculated. Kruskul Wallis chi square test was used to test the significance of difference between quantitative variables and Yate's chi square test for qualitative variables. A'p'value less than 0.05 is taken to denote significant relationship. ${ }^{9-10}$

\section{Results}

Group A: Patients for whom surgery done under laparoscopy technique

Group B: Patients for whom laparoscopy was converted to open technique

Group C: Patients for whom surgery done under open technique

\section{A: Profile of Cases Studied}

Table 1: Age Distribution

Age of patients included in the study was $49.2 \pm$ 13.1 years. There was no statistically significant difference in the age distribution of the patients in the three groups ('p' $=0.1936)$. 


\section{Age Distribution}

\begin{tabular}{|c|c|c|c|c|c|c|c|c|}
\hline \multirow{2}{*}{ Age Group } & \multicolumn{2}{|c|}{ Group A } & \multicolumn{2}{|c|}{ Group B } & \multicolumn{2}{|c|}{ Group C } & \multicolumn{2}{|c|}{ Total } \\
\hline & No & $\%$ & No & $\%$ & No & $\%$ & No & $\%$ \\
\hline Less than 40 yrs & 2 & 20 & - & - & 8 & 32 & 10 & 25 \\
\hline $40-57$ years & 6 & 60 & 3 & 60 & 9 & 36 & 18 & 45 \\
\hline $60 \&$ above & 2 & 20 & 2 & 40 & 8 & 32 & 12 & 30 \\
\hline Total & 10 & 100 & 5 & 100 & 25 & 100 & 40 & 100 \\
\hline Range & \multicolumn{2}{|c|}{$35-65$} & \multicolumn{2}{|c|}{$50-70$} & \multicolumn{2}{|c|}{$37-78$} & \multicolumn{2}{|c|}{$20-78$} \\
\hline Mean & \multicolumn{2}{|c|}{48.4} & \multicolumn{2}{|c|}{58.4} & \multicolumn{2}{|c|}{47.6} & \multicolumn{2}{|c|}{49.2} \\
\hline S.D & \multicolumn{2}{|c|}{10.5} & & & \multicolumn{2}{|c|}{14.4} & \multicolumn{2}{|c|}{13.1} \\
\hline 'p' & \multicolumn{8}{|c|}{$\begin{array}{c}0.1936 \\
\text { Not significant }\end{array}$} \\
\hline
\end{tabular}

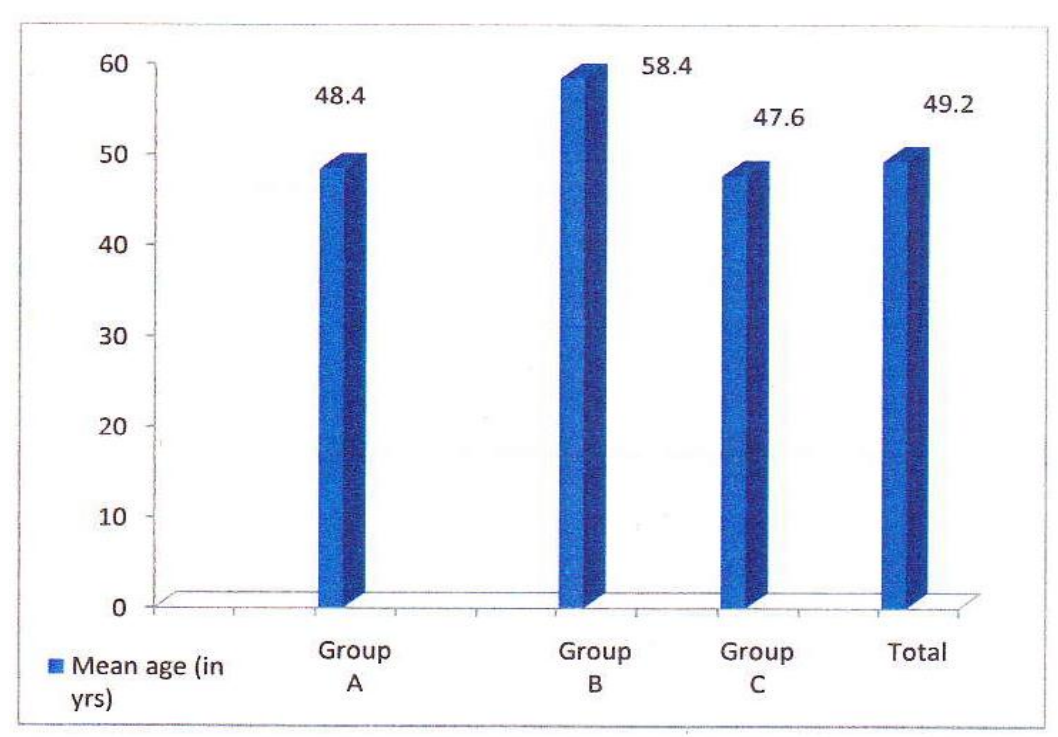

Table 2: Intestinal Obstruction

\begin{tabular}{|l|c|c|c|c|c|c|c|c|}
\hline \multirow{2}{*}{$\begin{array}{l}\text { Intestinal } \\
\text { Obstruction }\end{array}$} & \multicolumn{2}{|c|}{ Group A } & \multicolumn{2}{c|}{ Group B } & \multicolumn{2}{c|}{ Group C } & \multicolumn{2}{c|}{ Total } \\
\cline { 2 - 9 } & No & $\%$ & No & $\%$ & No & $\%$ & No & $\%$ \\
\hline Impending & - & - & - & - & 2 & 8 & 2 & 5 \\
\hline Present & -- & - & - & - & 6 & 24 & 7 & 17.5 \\
\hline Absent & 10 & 100 & 5 & 100 & 17 & 68 & 31 & 77.5 \\
\hline Total & 10 & 100 & 5 & 100 & 25 & 100 & 40 & 100 \\
\hline
\end{tabular}

Intestinal obstruction was present in $24 \%$ in group C. it was absent in all 10 cases in group A \& 5 cases in group B INTESTINAL OBSTRUCTION

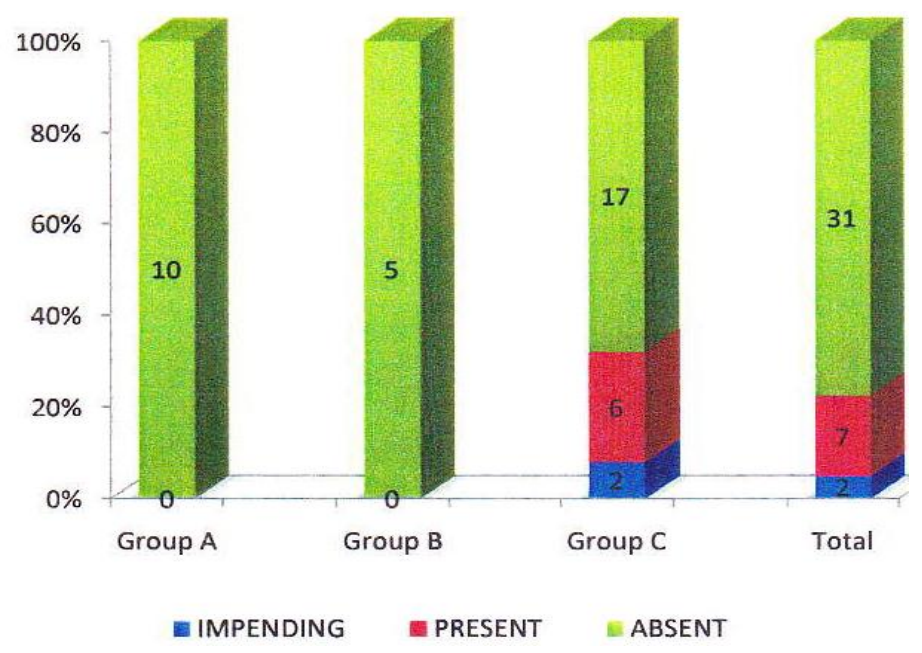




\section{JMSCR VoI||07||Issue ||07||Page 114-122||July}

Table 3: Liver Metastasis

\begin{tabular}{|l|c|c|c|c|c|c|c|c|}
\hline \multirow{2}{*}{ Livermets } & \multicolumn{2}{|c|}{ Group A } & \multicolumn{2}{c|}{ Group B } & \multicolumn{2}{c|}{ Group C } & \multicolumn{2}{c|}{ Total } \\
\cline { 2 - 9 } & No & $\%$ & No & $\%$ & No & $\%$ & No & $\%$ \\
\hline Present & 2 & 20 & 1 & 20 & 2 & 8 & 5 & 12.5 \\
\hline Absent & 8 & 80 & 4 & 80 & 23 & 92 & 35 & 87.5 \\
\hline Total & 10 & 100 & 5 & 100 & 25 & 100 & 40 & 100 \\
\hline
\end{tabular}

Livermets was present in $25 \%$ of cases in group A \& B, Whereas it was found only $8 \%$ in cases in group C.

\section{Liver Mets}

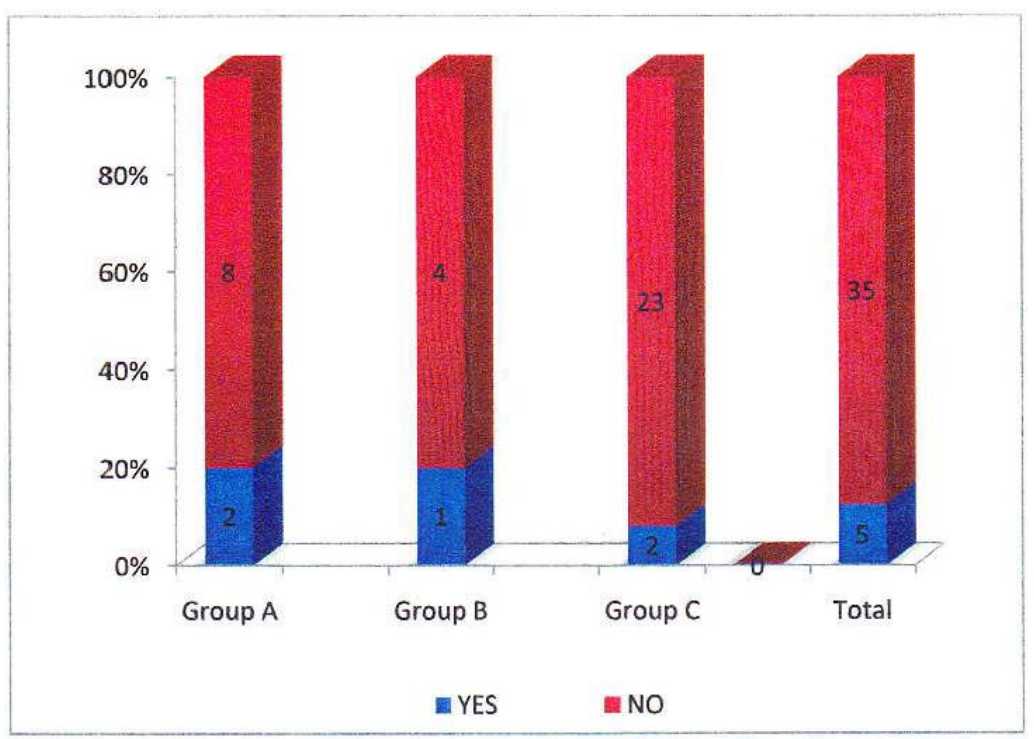

Table 4: Procedure Done

\begin{tabular}{|l|c|c|}
\hline \multirow{2}{*}{ Procedure Done } & \multicolumn{2}{|c|}{ Cases } \\
\cline { 2 - 3 } & No & \% \\
\hline A:Laparoscopy & 10 & 25 \\
\hline B:Laparosopy converted to open & 5 & 12.5 \\
\hline C: Open technique & 25 & 62.5 \\
\hline Total & 40 & 100 \\
\hline
\end{tabular}

Laparoscopy was done in $25 \%$ of cases included in the study. Another $12.5 \%$ of Laparoscopy cases were converted to open technique due to medical reasons. Open technique was adopted in $62.5 \%$ of cases in the study.

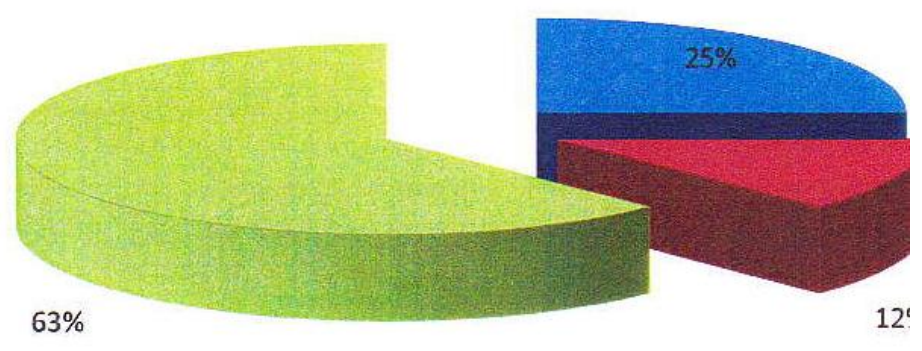

I IAP. 
B : Comparative Efficacy Of The Three Techniques

Table 5: Hospital Stay

\begin{tabular}{|l|c|c|c|}
\hline \multirow{2}{*}{ Group } & \multicolumn{3}{|c|}{ Hospital Stay (in days) } \\
\cline { 2 - 4 } & Range & Mean & SD \\
\hline Lap & $10-15$ & 12.0 & 1.56 \\
\hline Lap to open & $14-16$ & 14.8 & 1.1 \\
\hline Open & $11-21$ & 14.83 & 3.06 \\
\hline Total & $10-21$ & 14.1 & 2.82 \\
\hline P & \multicolumn{3}{|c|}{ 0.007 Significant } \\
\hline
\end{tabular}

Hospital stay was minimum (12 \pm 1.56 days $)$ in laparoscopy technique cases and maximum (14.83 \pm 3.06 days) in open technique cases. The differences were statistically significant. (' $\mathrm{p}$ ' = 0.007)

\section{Hospital Stay}

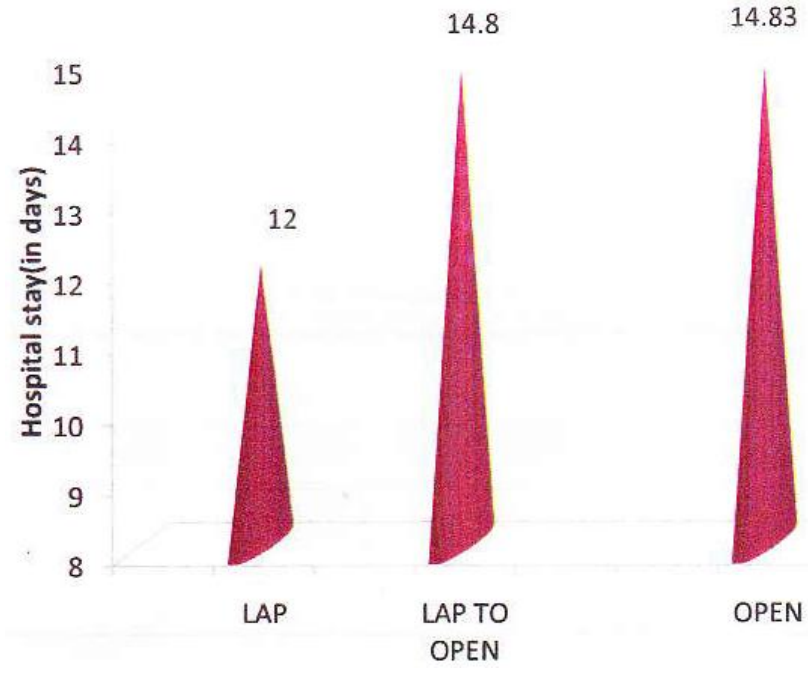

Table 6: Post Operative Complications

\begin{tabular}{|l|c|c|c|c|c|c|c|}
\hline \multirow{2}{*}{ Group } & \multirow{2}{*}{$\begin{array}{c}\text { No. Of } \\
\text { cases }\end{array}$} & \multicolumn{6}{|c|}{ Complications Present } \\
\cline { 3 - 8 } & & Wound infection & \multicolumn{2}{|c|}{ Wound } & \multicolumn{2}{c|}{ Sepsis } \\
\hline & & No & $\mathbf{\%}$ & No & \% & No & \% \\
\hline Lap & $\mathbf{1 0}$ & - & - & - & - & - & - \\
\hline Lap to open & $\mathbf{5}$ & 4 & 80 & 1 & 20 & - & - \\
\hline Open & $\mathbf{2 5}$ & 7 & 28 & 5 & 20 & 1 & 4 \\
\hline Total & $\mathbf{4 0}$ & 11 & 27.5 & 6 & 15 & 1 & 2.5 \\
\hline
\end{tabular}

Complications were completely absent in laparoscopy technique cases.

Follow Up Complications

Table 7: Local Recurrence / Wound Site Port Site Recurrence

\begin{tabular}{|l|c|c|c|c|c|}
\hline \multirow{2}{*}{ Group } & \multirow{2}{*}{ No of cases } & \multicolumn{4}{|c|}{ Complications present } \\
\cline { 3 - 6 } & & \multicolumn{2}{|c|}{ Local recurrence } & \multicolumn{2}{c|}{ Wound site/Port site } \\
\cline { 3 - 6 } & 10 & - & - & 1 & No \\
\hline Lap & 5 & - & - & - & - \\
\hline Lap to open & 25 & 4 & 10 & - & - \\
\hline Open & 40 & 4 & 10 & 1 & 2.5 \\
\hline Total & & \multicolumn{4}{|l}{} \\
\hline
\end{tabular}




\section{Discussion}

40 patients diagnosed to have colorectal malignancy were included in our study. ${ }^{11}$ Our study was predominated by male population who accounted for approximately two thirds of the study population. ${ }^{12}$ In our study, patients between age group of 40 - 59 yrs were commonly affected by colorectal cancers which accounted for 18 patients, followed by 12 patients in the age group more than $60 \mathrm{yrs}$ and 10 patients in the age group more than 40 yrs. $^{13}$ Patients with carcinoma rectum were most commonly encountered in our study which contributed to more than half of the study population followed by 6 patients with sigmoid colon growth, 5 patients with ascending colon and hepatic flexure growth, 4 patients with caecal growth and 2 patients with transverse colon malignancy in the order of decreasing frequency. ${ }^{14}$ In our study we did not encounter any patient with descending colon growth. Out of the 40 cases, patients were taken up for either laparoscopic or open procedure by taking into consideration the various like their co- morbidities and tumor size, with h/o previous surgery and nature of presentation (with or without obstruction) being an important factor. Based on the above mentioned factors, 25 patients were operated using open technique and 15 patients were considered for laparoscopic approach. ${ }^{15-16}$ Among the 15 patients taken up for laparoscopic approach, 5 were converted to open approach due to one of the following reasons encountered during laparoscopic approach: Tumor invasion into adjacent organs (bladder), Difficult dissection, Uncertainty of tumor clearance, Anesthetic complications- intraoperative hypertension due to hypercarbia and COPD in one case. $^{17}$

Comparing the various data which were observed during both laparoscopic and open procedures, there was a comparable reduction in blood loss for those patients who underwent laparoscopic surgeries, We were able to obtain an adequate oncological clearance with negative surgical margins in all patients who underwent surgery, immaterial Of whether they underwent laparoscopic or open surgery. Thus in our study, we successfully achieved negative margins for all patients who underwent laparoscopic approach. On analysing the post-operative specimen of all patients, the no. of lymph nodes retrieved and the positive nodes obtained were almost similar in figures in both laparoscopic and open approaches. The mean duration of surgery for patients who underwent open approach (101.8mins) was less when compared to that group which was operated by laparoscopic approach (124 mins). This difference may be probably due to the less exposure to laparoscopic colorectal procedures of our surgeons. ${ }^{18-20}$

For post-operative pain relief, the mean need of parenteral narcotics was for 4 days for open surgery which was reduced to 2 days in laparoscopic surgery. Also we found that when patients were operated by laparoscopic approach, none of them had any wound infection / dehiscence or sepsis in their postoperative period. But among open cases, 11 patients had wound infection, with wound dehiscence in 6 patients. The wound dehiscence was mainly of the perineal wound rather than the abdominal wound. ${ }^{21}$ Also one patient died of sepsis during the postoperative period. The mean hospital stay was 12 days for lap versus 15 for open. The reduced length of stay associated with laparoscopic approach is multifactorial and includes an earlier tolerance of oral intake, shorter duration of parenteral narcotic requirement and earlier return of gastrointestinal function. The elimination of midline laparotomy incision enabled better colostomy care. ${ }^{22}$

All the cases were followed up in regular intervals, for a varying period between 3 to 24 months. CEA levels were monitored during follow up. Incidence of local recurrence was 4 in open case, with one case of port site recurrence in laparoscopic surgery, and one case of distant metastasis in laparoscopic approach which is explained by the aggressiveness of the tumor per se.Port site recurrence should be considered equivalent to that of wound recurrence after open 
approach and should not be viewed as increased risk associated with laparoscopy. ${ }^{23}$

Thus as a whole, it can be stated that the operative morbidity and the various post-operative complications encountered were much Iess for laparoscopically operated patients are comparison with open surgical group. ${ }^{24}$

\section{Review of Literature}

Three large multi-institutional prospective randomized trials beginning in the 1990s are available for minimally invasive surgery for colorectal cancer. These include:

1. The Clinical Outcomes of Surgical Therapy (COST) Study Group trial in the United States and Canada,

2. The Colon Carcinoma Laparoscopic or Open Resection (COLOR) trial in Europe, and the

3. Medical Research Council Conventional versus Laparoscopic-assisted Surgery in Colorectal Cancer (MRC CLASICC) trial in the United Kingdom.

The COST trial

- started in August 1994 and ended in August 2001 with accrual of patients with histologically confirmed adenocarcinoma of the colon with the intent to show that laparoscopic colectomy and open colectomy have similar outcomes.

- The primary endpoint was time to tumour recurrence

- Secondary endpoints were disease free survival, complications, variables related to recovery and are quality of life. The findings showed that there were no significant differences between either group with respect to time to recurrence, disease-free survival, or overall survival for any stage. A significant difference was shown by

- shorter hospital stay in the laparoscopic group versus the open group $(5$ versus 6 days, $\mathrm{p}<$ 0.001),

- less use ofintravenous narcotics (3 versus 4 days, $\mathrm{p}<0.001$ ), and
- 1 ess use oforal narcotics (1 versus 2 days, $\mathrm{p}<$ 0.001) [9]. The laparoscopic group did show a significantly longer operative time in comparison to the open group (150 versus 95 minutes, $\mathrm{p}<0.001)$. These findings indicate that laparoscopic colectomy is a safe, oncologic, operative approach for colon cancer and has other added benefits as well.

\section{The COLOR trial}

- started in March 1997 and ended March 2003.

- The primary endpoint of the study was disease-free interval at 3 years

- Secondary endpoints were short-term morbidity and mortality, number of positive resection margins, local recurrence, pod-site or wound-site recurrence, and blood loss during surgery. The combined disease-free survival at 3 years for all stages in the laparoscopic group was $74.20 \%$ for the open group was $76.2 \%$. The disease-free survival difference was small supporting the use of laparoscopic colectomy for colon cancer.

The MRC CLASICC trial

- $\quad$ started in July 1996 and ended June 2002.

- The primary endpoints were overall survival, disease-free survival, and local recurrence rates at 3 years.

- Secondary outcomes were distal recurrence rates, wound/port-site recurrence rates and quality-of life.

- There was no statistical difference in the overall survival $(68.4 \%$ versus $66.70 \%)$, disease-free survival $(66.3 \%$ verses $67.7 \%)$, or 3-year local recurrence rate between laparoscopic and open groups, respectively (8.6\% versus $7.9 \%)$. This trial concluded similar outcomes in patients undergoing laparoscopic surgery versus open surgery for colon cancer.

- Currently only the CLASICC trial has specifically addressed rectal cancer. Short term results of the CLASICC trial showed similar complication rates and short term outcomes between laparoscopic and open surgery for rectal cancer. 
Based on RCT'S reporting on short term \& long term oncologic outcomes, along with margins \& lymph node adequacy, there is a strong evidence to confirm that a laparoscopic resection is oncologically equivalent to open for colon cancer.With respect to rectal cancer, available data confirm the short-term safety of a laparoscopic approach to rectal cancer. Laparoscopic resection for rectal cancer is feasible with the quality of mesorectal excision and postoperative outcomes similar to those of open surgery.

\section{Conclusion}

In our study, out of 40 patients of colorectal cancers, after evaluating various criterions, 10 were operated by laparoscopic technique and 30 underwent open procedure. The various postoperative complications and morbidity encountered in laparoscopic group was comparatively less than that of open group. Also in terms of oncological clearance and safety, there was no significant difference between both the groups. Ours has been a small study with study population of 40 cases followed for maximum of 24 months. To make our study results statistically significant, this study can be extended to a larger population $\&$ for a longer duration. On extending the study to a larger population, further details with reference to its place in early/late colorectal cancer, locoregional clearance will be obtained. Further if screening programs to detect early cancers a.re available, then the yield from laparoscopic surgery would increase. On extending the study to a longer duration, fuilher knowledge about its impact on disease free survival, overall survival, morbidity will be obtained Minimally invasive surgery is currently feasible in experienced hands. ${ }^{25}$ Laparoscopy has undoubtedly surpassed open surgery with its benefits of smaller incision, reduced postoperative pain, decreased post op narcotic requirement, shorter hospital stay \& quicker recovery. There is no increase in complication rate. The longer duration of surgery $\&$ the steep learning curve of the surgeon are practical concerns, which ought to be accepted, laparoscopy being an emerging \& evolving field in the area of colorectal surgery. Thus, with further research, appropriateness of laparoscopy in colorectal surgery will be further defined. $^{26}$

\section{References}

1. Bailey and love, 25ft edition, Short practice of surgery

2. Manigot's abdominal operations- 11 'h edition

3. Nyhus, Mastery of surgery- $5 \mathrm{ft}$ edition

4. Sabiston- textbook of surgery, 18 s edition

5. Schwarlz Principle of surgery, 9ft edition

6. Skandalakis- Surgical anatomy

7. Zollinger's atlas of surgical operations 8tr'edition

8. Art of laparoscopic surgery, Textbook and atlas by Dr.C.Palanivelu

9. Laparoscopic surgery of the abdomen, by Bruce Mac Fadyen

10. Ravi j. Chokshi et al. Surgical management of colorectal cancer. A review of literature. Indian Joumal of Surgery (nov -dec 2009), 71:350-355

11. Sergio Huedo et al.Current evidence based options in the management of adenocarcinoma of the rectum. Indian Jour:nal of Surgery ( nov- dec 2009), 71:356-362

12. Parul. J. Shukla et al.Current status of laparoscopic surgeries in gastrointestinal malignancies. Indian Joumal of Sugery (oct- dec 2008),70:261-264

13. S. Biondo et al, Quality of mesorectum after laparoscopic resection for rectal cancer - results of an audited teaching programme in Spain. The Authors. Joumal Compilation, j.1463-1318, 2008. 01720.x

14. M. Braga et al, Randomised clinical trial of laparoscopic versus open left colonic resection, British Joumal of Surgery 2010, 97:1 180-1 186. 
15. M .G. Tltherleigh et al, Management of early rectal cancer, British Joumal of Surgery, 2008, 95: 409-423.

16. M. Pascual et al, Randomized clinical trial comparing inflammatory and angiogenic response after open versus laparoscopic curative resection for colorectal cancer. British joumal of Surgery, 2010.97 :1 6381645.

17. D.G. Jayne et al, Five years follow up of the Medical Research Council CLASICC trial of laparoscopically assisted versus open surgery for colorectal cancer. Bristish Joumal of Surgery, 2010; 97:1638-1645.

18. Seiichiro Yamomoto et al, Phase II trial to evaluate laparoscopic surgery for stage 0/1 rectal carcinoma. Japan Joumal of clinical oncology 2008; 38 (7) 497 -500.

19. Karl Y. Bilimoria et al, Use \& outcomes of laparoscopic assisted colectomy for cancer in the united states , Archives of Surgery, vol 143 (no.9), Sep 2008.

20. Short term endpoints of conventional versus laparoscopic assisted surgery in patients with colorectal cancer (MRC CLASICC trial), Multicentre, randomized controlled trial. Lancet 365 : 1718 -1 7 26, 2005.

21. Colon and rectum cancer staging by American Joint Committee on Cancer, $7 \mathrm{~s}$ ed.

22. Malhew. C. Koopman, et al, Laparoscopic and minimally invasive resection of malignant colorectal diseases. Surgical clinics of North America.88 (2008) 1047t072.

23. Wilkinson et al. Surgical therapy for colorectal Adenocarcinoma. Gastroenterology clinics of North America,3T (2008) 253-267.

24. Kenneth L. Meredith et al, The multidisciplinary management of rectal cancer. Surgical clinics of North America. 89 (2009) 177-215.
25. A comparison of laparoscopically assisted and open colectomy for colon cancer, $\mathrm{N}$ Engl J Med 2004; 350 (20):2050-2059.

26. History of laparoscopic surgery by Garth H. Ballantlare. 